\title{
Differential Expression of Members of the $\beta$-Galactosidase Gene Family during Japanese Pear (Pyrus pyrifolia L.) Fruit Growth and On-tree Ripening
}

\author{
Akira Tateishi ${ }^{1}$ and Kenji Nagashima \\ College of Bioresource Sciences, Nihon University, Fujisawa, Kanagawa 252-8510, Japan
}

Francis M. Mathooko

Department of Food Science and Technology, Faculty of Agriculture, Jomo Kenyatta University of Agriculture and Technology, P.O. Box 62000, Nairobi 00200, Kenya

Mercy W. Mwaniki, Yasutaka Kubo, and Akitsugu Inaba

Laboratory of Postharvest Agriculture, Faculty of Agriculture, Okayama University, Tsushima, Okayama 700-8530, Japan

\author{
Shohei Yamaki \\ Graduate School of Bioagricultural Science, Nagoya University, Nagoya, Aichi, 464-8601 \\ Hiroaki Inoue \\ College of Bioresource Sciences, Nihon University, Fujisawa, Kanagawa 252-8510, Japan
}

\begin{abstract}
AdDitional InDEX words. cell wall, cloning, fruit softening, galactose, phylogenetic tree
Aвstract. Galactosidases are thought to play a key role in cell wall metabolism during fruit growth and ripening. In this study we cloned seven $\beta$-galactosidase ( $\beta$-Gal) cDNAs from japanese pear fruit and designated them $P p G A L 2, P p G A L 3$, $P p-G A L 4, P p G A L 5, P p G A L 6, P p G A L 7$, and $P p G A L 8$, in addition to the previously described $J P-G A L$ hereinafter termed $P$ PAL1. mRNA expression patterns of these clones were characterized throughout fruit growth and on-tree ripening, and in leaves and shoots in three japanese pear cultivars, 'Housui', 'Kousui', and 'Niitaka'. The shared amino acid sequence identity among the eight japanese pear $\beta$-Gal $(P p G A L)$ clones ranged from $50 \%$ to $60 \%$. They all contained the putative active site containing consensus sequence pattern G-G-P-[LIVM](2)-x(2)-Q-X-E-N-E-[FY] belonging to glycoside hydrolase family 35 . Expression of all the clones was both development- and tissue-specific. $P p G A L 1$ and $P p$ $G A L 4$ were only expressed in the ripe fruit while $P p G A L 2$ and $P p G A L 3$ were expressed in both expanding and ripening fruit with their abundance being highest in the ripe fruit. The abundance of PpGAL5, PpGAL6, and PpGAL7 mRNAs was highest in expanding fruit but decreased drastically upon the onset of ripening. PpGAL8 was only detected in very young fruit (15 days after full bloom) and not in expanding and ripening fruit. These results indicate that in japanese pear fruit $\beta$-Gal is encoded by a multigene family whose members show distinct and overlapping expression during the various phases of fruit development. Some of the members are not only fruit-specific but also ripening-specific and, therefore, may play a crucial role in cell wall disassembly during japanese pear fruit softening.
\end{abstract}

Fruit growth and ripening occur as a result of a myriad of both physiological and biochemical processes. While some of these processes cease upon attainment of maturity, others continue into the senescence phase. Since the extensibility of the cell wall constrains expansion, cell wall loosening is necessary in order to allow turgor-driven cell enlargement to occur (Cosgrove, 1997; Rose et al., 2003). The cell wall of expanding tissues possesses numerous enzymes, among them $\beta$-galactosidase [ $\beta$-Gal (EC 3.2.1.23)], which contribute to modification of its mechanical properties (Brummell and Harpster, 2001). Some of the enzymes involved

Received for publication 6 Oct. 2004. Accepted for publication 18 Dec. 2004. 1To whom correspondence should be addressed; e-mail: tateishi@brs.nihonu.ac.jp

${ }^{3}$ Dr. F.M. Mathooko was supported by a Japan Society for the Promotion of Science (JSPS) Invitation Fellowship for Research in Japan.

The authors are grateful to Prof. Naoki Sakurai, Hiroshima Univ., for helpful discussion. The phylogenetic tree was drawn with the assistance of Dr. Koichiro Ushijima, Okayama Univ. We thank Mr. M. Shinohara, Yokohama City, Kanagawa Prefecture, for assisting in growing of the pear fruits. in cell wall metabolism, such as expansins, not only have a role in facilitating the expansion of plant cells but also contribute to cell wall disassembly in nongrowing ripening tissues (Rose and Bennett, 1999; Rose et al., 1997, 2003). $\beta$-Gals are characterized by their ability to hydrolyze terminal, nonreducing $\beta$-D-galactosyl residues from numerous substrates. In higher plants, the enzyme cleaving $\beta$-1,4-galactan in endo fashion has not been identified, and $\beta-\mathrm{Gal}$ is the only enzyme that is able to hydrolyze galactosyl residues from cell wall polysaccharides (Smith et al., 1998). Also, $\beta$-Gal action has been proposed to release stored energy for rapid growth, release free galactose during normal metabolic recycling of glycolipids and glycoproteins, and to degrade cell wall compounds during senescence (Smith and Gross, 2000).

Enzymes of $\beta$-Gal have been isolated from various fruit, including tomato (Lycopersicon esculentum Mill.) (Carey et al., 1995), avocado (Persea americana Mill.) (Tateishi et al., 2001a), and japanese pear (Kitagawa et al., 1995), and have been characterized in relation to removal of galactosyl residues during fruit softening. The $\beta$-Gals so far isolated consist of several isoforms that have 
different activity levels against native and synthetic substrates and during fruit development and/or ripening. The disassembly of the fruit cell wall is largely responsible for softening and textural changes during ripening, but the precise roles of particular cell wall alterations and/or of cell wall-modifying enzymes that bring about these changes are not clearly understood (Brummell and Harpster, 2001). Among the three $\beta-\mathrm{Gal}$ isoforms from tomato fruit, only isoform II was able to release galactosyl residues from pectic polysaccharides (Carrington and Pressy, 1996). AV-GAL III, one of the $\beta$-Gal isoforms from avocado fruit, is the most active against native cell wall polysaccharides compared to the other isoforms and its activity increases with fruit softening (Tateishi et al., 2001a). cDNAs encoding for softening-related $\beta-\mathrm{Gal}$ isoforms have also been isolated from tomato (Smith et al., 1998) and japanese pear (Tateishi et al., 2001b). Using antisense suppression of isoform II encoded by $T B G 4$ from tomato fruit, it has been demonstrated that this isoform plays a significant role in fruit softening (Smith et al., 2002).

Although there are many reports on $\beta$-Gal involvement in fruit softening, the role of $\beta$-Gal in the modification of cell wall architecture during pear fruit growth has not been fully established. At least five $\beta$-Gals with different substrate specificity are present in ripe japanese pear fruit (Kitagawa et al., 1995). On the other hand, the activity of $\beta$-Gal is high throughout japanese pear fruit development with further increase occurring during fruit ripening (Tateishi et al., 1996, 2001b; Yamaki and Kakiuchi, 1979). It is plausible, therefore, that some of the $\beta$-Gal isoforms and genes could be developmentally regulated besides playing key roles in cell wall disassembly during japanese pear fruit ripening. As a first step in understanding the role of $\beta-$ Gal in pear fruit growth and ripening, we isolated cDNA clones of $\beta$-Gal from japanese pear fruit and studied their expression patterns during fruit growth and on-tree ripening. Analysis of each of the eight genes in the japanese pear fruit $\beta$-Gal gene family will give an insight into the role each plays in galactose metabolism and cell wall turnover during fruit growth and ripening.

\section{Materials and Methods}

Plant Materials. Japanese pear fruit were harvested from Shinohara Orchard, Yokohama City, Kanagawa Prefecture, Japan. Fruit of 'Housui' were picked at 15, 30, 45, 60, 75, 90, 105, 120, and $135 \mathrm{~d}$ after full bloom (DAFB). At 135 DAFB, the fruit had attained optimum maturity for eating. Fruit of 'Kousui' were picked at 15, 30, 60, 90, and 120 DAFB while those of 'Niitaka' were picked at 15, 30, 60, 90, 120, 150, and 165 DAFB. Fruit of 'Kousui' and 'Niitaka' harvested at 120 and 165 DAFB, respectively, had attained the optimum maturity for eating. Young leaves (pre-expanding), expanding leaves ( $<5 \mathrm{~cm}$ long), mature leaves (fully expanded, 7 to $10 \mathrm{~cm}$ long), and shoots $(\approx 5 \mathrm{~mm}$ diameter) were sampled from each cultivar and used for RNA extraction. The fruit were peeled and cored, and the leaves and shoots were immediately frozen in liquid nitrogen and stored at $-85^{\circ} \mathrm{C}$ until RNA extraction.

RNA EXTRACTION. Frozen samples were ground into a fine powder using a mortar and pestle in the presence of liquid nitrogen. Total RNA was extracted using the hot-borate method of Wan and Wilkins (1994) with an extraction buffer containing Nonidet P-40, polyvinylpyrolidone-40 (PVP-40), and sodium deoxycholate (Tateishi et al., 2001b).

Construction of CDNA Library. Poly(A)+ RNA was isolated using PolyATtract (Promega, Madison, Wis.) from mixed total RNA extracted from 30 to 135 DAFB 'Housui' fruit samples. This was used to generate a Lambda ZAP II library with Uni-ZAP XR vector system (Stratagene, La Jolla, Calif.) (Tateishi et al., 2002). The first strand cDNA was synthesized using SuperScript II (Invitrogen, Carlsbad, Calif.) reverse transcriptase (RT) primed with oligo d(T)-nucleotides. The synthesis of the second strand cDNA and in vitro packaging were performed using Gigapack III Gold Packaging Extracts according to the manufacturer's instructions (Stratagene), except for the size fractionation of the cDNA using Size Fractionation Column (Invitrogen).

SCREENING OF $\beta$-GalactosidASE FROM THE CDNA LIBRARY AND RT-POLYMERASE CHAIN REACTION (RT-PCR). We screened the library under low-stringency conditions using Pstl and EcoRI fragments of JP-GAL as a probe (Tateishi et al., 2001b). The positive plaques were isolated and sequenced, and then obtained a cDNA clone encoding $\beta$-Gal (PpGAL4, see results) besides $J P-G A L$. On the other hand, total RNA was extracted from 'Housui' fruit harvested at 15 to 135 DAFB. A mixed $1 \mu \mathrm{g}$ of total RNA primed with NotI d(T)18 (5'-ACCT GGAAGAATTCGCGGCCGCAGGAA(T $)_{18^{-}} 3^{\prime}$ ) was used for reverse transcription. Degenerate primers were designed based on highly conserved amino acid sequences from apple (Malus $\times$ domestica Borkh.) (accession no. L29451; Ross et al., 1994), asparagus (Asparagus officinalis L.) (accession no. X77319; King and Davies, 1995), broccoli (Brassica oleracea L.) (accession no. X84684; Downs and Almira, 1995), mango (Mangifera indica L.) (accession no. AF064786; Othman et al., 1998), and JP-GAL isolated from japanese pear [accession no. AB046543 (renamed PpGAL1); Tateishi et al., 2001b]. These are the same primers used by Smith et al. (1998) to isolate tomato $\beta-\mathrm{Gal}(T B G)$ genes. Approximately, 800 base pairs (bp) product was amplified by the first PCR using JPG-D1 (5'-WSNGGNWSNATHCAYTAYCC-3') and JPG-DC1 (5'-CCRTAYTCRTCNADNGGNGC-3') primers. The product was subjected to electrophoresis and the amplified band was recovered from the gel using QIAEX II (QIAGEN, $\mathrm{GmbH}$, Hilden, Germany) and used as the template DNA for the second PCR using JPG-D2 (5'-ATHCARACNTAYGTNTTYTGG-3') and JPG-DC1 primers. The amplified band $(\approx 700$ bp) was extracted from the gel after electrophoresis and ligated into pGEM-T vector (Promega) according to the manufacturer's instructions and sequenced. Anew six $\beta$-Gal clones were isolated besides $J P-G A L$ and $P p G A L 4$. RNA probes were synthesized from the resultant clones using digoxigenin (DIG) RNA-labeling kit (Roche Diagnostics, Basel, Switzerland). The probes were used for hybridization to screen the full-length $\beta$-Gal (PpGAL5, 6 and 7 , see results) from japanese pear fruit cDNA library under high stringency conditions. The other full-length $\beta$-Gal clones (PpGAL2, PpGAL3, and PpGAL8, see results) were isolated by RACE (rapid amplification of cDNA ends) PCR method (see below).

RAPID AMPLIFICATION OF CDNA ENDS (RACE). RACE method was also used for the isolation of full-length $\beta$-Gal cDNAs (PpGAL2, PpGAL3, and PpGAL8, see results) with GeneRacer Kit (Invitrogen) or 5' RACE system for Rapid Amplification of cDNA Ends (version 2.0; Invitrogen). First strand cDNA was synthesized GeneRacer oligo dT primer supplied with the kit or NotI d(T)18. Then, first PCR performed using gene specific primer for each clone and GeneRacer 5' primer or Abridged Anchor primer, both were supplied with the kits. Gene-specific primers used for first RACE-PCR were PpGAL2-GSP1 (5'TTCTGACCAAATTGCCCTTCAATA-3'), PpGAL3-GSP1 (5'AGGTTTGTTCTGATAGATAGGCGT-3') and PpGAL8-GSP1 
(5'-CCCAGGTCATATATGCATAA-3') for PpGAL2, PpGAL3, and $P p G A L 8$, respectively. The each PCR product was used as template for nested PCR. The primers used nested PCR were gene specific nested primer and GeneRacer $5^{\prime}$ nested primer or Abridged Anchor primer, both were supplied with the kits. The primers using nested PCR were following, $P p G A L 2-\mathrm{GSP} 2$ (5'-GAGATAGAGTCCACTGGCTCGCA-3'), PpGAL3-GSP2 (5'-AAGGGACACCTATATTCTGAGAA-3') and $P p G A L 8$ GSP2 (5'-GAACCGTCTTTATGAACCGA-3') for PpGAL2, $P p G A L 3$, and $P p G A L 8$, respectively. The amplified each fragment was cloned and sequenced, and then synthesized start primers for each clone based on resultant sequencing data. Finally, full-length cDNA clones of PpGAL2, PpGAL3, and PpGAL8 were amplified using high-fidelity DNA polymerase $(P f x$ DNA polymerase; Invitrogen) with each start primer and Not I d(T)18 using cDNA template pre-synthesized with NotI d(T)18. Start primers were used following, $P p G A L 2$-start (5'-TCATCTCTTTTCCGCGCACA-3'), PpGAL3-start (5'-GCCAACCAACCATGTTCCCA-3') and $P p G A L 8$-start (5'-TTCTGCTCTGCTGCTGCATA-3') for $P p G A L 2, P p G A L 3$, and $P p G A L 8$, respectively.

DNA SEQUENCING AND SEQUENCE ANALYSIS. DNA sequencing was carried out using Cy5 Thermo Sequenase Dye Terminator Kit or Auto Read Sequencing Kit (Amersham Pharmacia Biotech, Piscataway, N.J.) and ALF Express II DNA sequencer (Amersham Pharmacia Biotech). BLAST and CLUSTAL W programs (Thompson et al., 1994) were used to search for homology against nucleotide and deduced amino acid sequences, respectively. Eukaryotic signal peptide prediction was conducted using SignalP (Nielsen et al., 1997). The targets of proteins deduced from each clone were analyzed using PSORT (Nakai and Kanehisa, 1992) and TargetP(Emanuelsson et al., 2000) programs, while the motifs were subjected to PROSITE program. The deduced amino acid sequences of the $P p G A L s$ were aligned with the corresponding sequences of other plant $\beta$-Gals. A phylogenetic tree was drawn using CLUSTAL W program.

RNA GEL-BLOT ANALYSIS. One microgram of total RNA was separated by electrophoresis on $0.8 \%$ formaldehyde denaturing agarose gel and transferred onto positively charged nylon membranes. The membranes were pre-hybridized at $68^{\circ} \mathrm{C}$ for $1 \mathrm{~h}$ in a solution containing $5 \times \mathrm{SSC}, 50 \%$ formamide, $1 \%(\mathrm{w} / \mathrm{v})$ blocking reagent (Roche Diagnostics), $0.1 \%(\mathrm{v} / \mathrm{v}) \mathrm{N}$-lauroylsarcosine and $0.02 \%(\mathrm{w} / \mathrm{v})$ SDS, followed by overnight hybridization in a similar solution containing the gene-specific DIG-labeled probes. RNAprobes were prepared mainly from the 3'-region of each $\beta$-Gal isozymes; the sequences corresponding to the probes were fulllength nucleotide sequences of 2293-2565 for PpGAL1, 896-3080 for PpGAL2, 1443-2845 for PpGAL3, 2314-2625 for PpGAL4, 2317-3310 for PpGAL5, 1629-3000 for PpGAL6, 1446-2730 for PpGAL7 and 1081-2901 for PpGAL8. After hybridization, the membranes were washed twice in $2 \times \mathrm{SSC}$ containing $0.1 \%(\mathrm{w} / \mathrm{v})$ SDS for $5 \mathrm{~min}$, followed by two washes in $0.1 \times$ SSC containing $0.1 \%(\mathrm{w} / \mathrm{v}) \mathrm{SDS}$ at $68^{\circ} \mathrm{C}$ for $15 \mathrm{~min}$. The hybridized signals were detected by DIG Nucleic Acid Detection Kit using CDP-Star (Tropix, Bedford, Mass.).

\section{Results}

Cloning and Phylogenetic analysis of $\beta$-galactoSIDASE GENE FAMILY. DNA gel-blot analysis was performed to determine the genetic organization of the $J P-G A L$ gene previously isolated from japanese pear fruit (Tateishi et al., 2001b). The ge- nomic DNA was digested with EcoRI, HindIII, SpeI, or XbaI. The probe used was prepared from upstream (5'-region) of $J P-G A L$ and gel-blot analysis carried out under low stringency conditions. In each case a single strong band was detected except for SpeI and $\mathrm{XbaI}$ digests in which some additional weaker bands were present (data not shown). These additional bands may represent other distantly related genes, thereby suggesting that in japanese pear fruit $\beta$-Gal is encoded by a multigene family. Following screening for cDNA library under low stringency condition with the cDNA fragment used for the Southern hybridization, PpGAL1, which previously had been cloned and designated JP-GAL (Tateishi et al., 2001b; accession no. AB046543) and PpGALA (accession no. AB190365), were isolated. cDNA fragments encoding different $\beta$-Gals besides PpGAL1 and PpGAL4 were obtained from RT-PCR with the degenerate primer sets based on the sequence obtained from the most conserved region of various fruit (see Materials and Methods). We screened the library using the cDNA fragments as probes in order to obtain the full-length cDNA clones and isolated $\beta$-Gals designated them PpGAL5 (accession no. AB190366), PpGAL6 (accession no. AB190367), and PpGAL7 (accession no. AB190368). Using RACE-PCR method, we further isolated full-length cDNAclones also encoding $\beta$-Gal and designated them PpGAL2 (accession no. AB190363), PpGAL3 (accession no. AB190364) and PpGAL8 (accession no. AB190369). Consequently, we obtained total eight cDNA clones (seven anew clones besides $P p G A L 1$ ) encoding $\beta$-Gal from japanese pear fruit.

Sequence analysis and properties of deduced amino acid sequences of the japanese pear $\beta$-Gal gene family (PpGALs) are summarized in Table 1. The length of $P p G A L \mathrm{cDNAs}$ ranged from 2643 to 3310 bp and encoded proteins of 725 to 903 amino acid residues. The molecular mass of the proteins predicted from the deduced amino acid sequences ranged from 80.9 to $101.0 \mathrm{kDa}$. The clones were divided into two classes depending on their predicted size. A smaller group including PpGAL1 and PpGAL4 encoded for ca. $80 \mathrm{kDa}$ proteins and the other clones encoded for 92 to $101 \mathrm{kDa}$ proteins with galactose binding lectin domain at the $\mathrm{C}$ terminal of the proteins (Fig. 1). They contained the putative active site containing consensus sequence pattern $\mathrm{G}$ G-P-[LIVM](2)-X(2)-Q-X-E-N-E-[FY] belonging to glycoside hydrolase family 35 (Henrissat, 1998) and also a predicted hydrophobic signal peptides that would be cleaved (Nielsen et al., 1997) (Fig. 1). All clones except PpGAL4 contained the N-linked glycosylation sites (1 to 7 sites) (Table 1; Fig. 1). PSORT and TargetP programs predicted that all $P p G A L$ proteins deduced from nucleotide sequences were exported to the outside of the plasma membrane (extracellular), and some clones were also targeted at plasma membrane or endoplasmic reticulum (Table 1).

We performed a phylogenetic analysis of several sets of $\beta$ Gal genes from various plant species to explore the evolutionary relationship of the japanese pear genes. A phylogenetic analysis based on amino acid sequence identity within selected $\beta$-Gal gene families grouped them into six main clusters (Fig. 2). PpGAL1 and $P p G A L 4$ aligned within a sublineage of cluster A containing among others apple and tomato $\beta$-Gal genes, which have been shown to play key roles in fruit ripening and softening; PpGAL5, PpGAL7 and PpGAL8 aligned within a sublineage of cluster C containing TBG6 and arabidopsis (Arabidopsis thaliana L.) genes; PpGAL6 and PpGAL2 belong to cluster F, which also has $T B G 5$ and $T B G 2$, which are expressed throughout tomato fruit development while $P p G A L 3$ belongs to the same cluster as $T B G 7$ among other arabidopsis $\beta$-Gal genes (cluster D). 
Table 1. Properties and bioinformatic analysis of the member of japanese pear $\beta$-galactosidase gene family.

\begin{tabular}{|c|c|c|c|c|c|c|}
\hline Clone & $\begin{array}{l}\text { Length } \\
\text { (bp) }\end{array}$ & $\mathrm{ORF}^{\mathrm{z}}$ & $\begin{array}{l}\text { Amino } \\
\text { acid }\end{array}$ & $\begin{array}{l}\text { Molecular } \\
\text { mass } \\
(\mathrm{kDa})\end{array}$ & N-link ${ }^{y}$ & Target \\
\hline$\overline{P p G A L 1}$ & 2,643 & $183-2,375$ & 731 & 80.9 & 1 & er $\mathrm{x} /$ outsidew $^{\mathrm{w}}$ \\
\hline PpGAL2 & 3,079 & $57-2,765$ & 903 & 101.0 & 7 & outside \\
\hline$P p G A L 3$ & 2,845 & $109-2,661$ & 851 & 94.9 & 9 & outside \\
\hline$P p G A L A$ & 2,687 & $204-2,378$ & 725 & 81.0 & 0 & er/outside \\
\hline PpGAL5 & 3,310 & $160-2,721$ & 854 & 94.7 & 1 & outside \\
\hline PpGAL6 & 3,000 & $329-2,854$ & 842 & 92.0 & 3 & outside \\
\hline PpGAL7 & 2,730 & $42-2,597$ & 852 & 94.8 & 2 & pmv/er/outside \\
\hline$P p G A L 8$ & 2,901 & $21-2,564$ & 848 & 93.9 & 2 & outside \\
\hline
\end{tabular}

EXPRESSION PATTERN OF THE $\beta$-GALACTOSIDASE GENES. We synthesized specific probes against each $\beta$-Gal isozymes (with no cross-hybridization, data not shown) and analyzed expression pattern of the members of the $\beta$-Gal gene family cloned herein during fruit growth and on-tree ripening in three cultivars of japanese pear. For 'Housui' fruit, cell division, fruit expansion, and ripening stages were up to 30,120 , and between 120 and 135 $\mathrm{DAFB}$, respectively. At $135 \mathrm{DAFB}$ the fruit is at the optimum maturity for eating. The fruit growth curve based on fruit weight exhibited the typical sigmoid curve (Fig. 3A). The accumulation of mRNA for $P p G A L I$ which encodes for the softening related $\beta$-Gal isozyme ( $\beta$-Gal III) in japanese pear fruit was first detected at $120 \mathrm{DAFB}$ and then increased at $135 \mathrm{DAFB}$ with the onset of fruit ripening (Fig. 3B). Accumulation of PpGAL4 mRNA was only detected in the fruit picked at 135 DAFB while that of $P p$ GAL2, PpGAL3, PpGAL5, and PpGAL6 mRNAs was observed during all the stages of fruit development (Fig. 3B). However, the pattern of accumulation of the mRNAs of these PpGAL genes was different. PpGAL2 and PpGAL3 mRNAs levels were low and relatively constant upto 75 DAFB and then started to increase with progress in fruit expansion and were highest in the ripe fruit. $P p G A L 5$ and $P p G A L 6$ mRNA levels remained fairly constant throughout fruit growth but decreased upon onset of fruit ripening at $120 \mathrm{DAFB}$ (Fig. 3B). Accumulation of PpGAL7 mRNA was also detected in 15 to 105 DAFB fruit but decreased to undetectable level upon onset of fruit ripening. mRNA for PpGAL8 was not detected at any stage of fruit growth and ripening irrespective of the length of time the film was exposed. RNA gel-blot analysis was performed to reveal whether any of the PpGAL genes were expressed in nonfruit tissues. $P p G A L 1$, $P p G A L 2, P p G A L 3, P p G A L 4$, and PpGAL8 mRNAs were not detected in immature, expanding, and mature leaves and shoots, while PpGAL5, PpGAL6, and PpGAL7 mRNAs were detected in all of them, albeit at low levels (Fig. 3C).

In this study we used two more japanese pear cultivars (Kousui and Niitaka) in order to compare the expression pattern of the members of the $\beta$-Gal gene family with those of 'Housui'. At 120 and 165 DAFB in 'Kousui' and 'Niitaka', respectively, the fruit is at the optimum maturity for eating. In 'Kousui', $P p G A L I$ and $P p G A L 4$ mRNAs were only detected in fully ripened fruit, that is at 120 DAFB as observed in 'Housui', although at low abundance. The abundance of PpGAL2 and PpGAL3 mRNAs increased with fruit growth and the highest accumulation occurred in fruit at $90 \mathrm{DAFB}$, whereas the abundance of PpGAL5
$P p G A L 6$ and $P p G A L 7$ mRNAs was high throughout fruit growth and decreased to undetectable levels upon onset of fruit ripening (Fig. 4B). As observed in 'Housui' and 'Kousui', in 'Niitaka', the accumulation of PpGAL1 and PpGALA mRNAs was only observed upon onset of fruit ripening while $P p G A L 2$ and $P p G A L 3$ mRNAs increased with fruit growth and ripening (Fig. 5B). The abundance of $P p G A L 5, P p G A L 6$, and $P p G A L 7$ mRNAs decreased with the onset of fruit ripening. In 'Kousui' and 'Niitaka' fruit, no $P p G A L 8$ mRNA accumulated during fruit growth and ripening. The expression pattern of the $\beta$-Gal genes in vegetative tissues in both 'Kousui' and 'Niitaka' was similar to that observed in 'Housui' (Fig. 4C and 5C).

\section{Discussion}

In japanese pear, five $\beta$-Gal isoforms have been shown to have different activities against artificial substrate and/or native cell wall polysaccharides extracted from fruit cell wall (Kitagawa et al., 1995). It is plausible, therefore, that the five isoforms are encoded by different genes and may not be as a result of protein modification after transcription, thereby qualifying to be classified as isozymes. Southern hybridization revealed the presence in the genomic DNA of other genes closely related the JP-GAL (data not shown), thereby leading to the conclusion that the japanese pear $\beta$-Gal isoforms are encoded by a multigene family. Consequently, we obtained anew seven $\beta$-Gal clones from japanese pear fruit besides $J P-G A L$ hereby designated $P p G A L 1$. All the amino acid sequences deduced from the eight cDNA clones contained the putative active site-containing consensus sequence pattern GG-P-[LIVM](2)-x(2)-Q-x-E-N-E-[FY] belonging to glycoside hydrolase family 35 (Henrissat, 1998) (Fig. 1). This suggests that all the eight clones have $\beta$-Gal activity although this may not be sufficient enough to make it possible to predict their in vivo substrate specificities (Smith and Gross, 2000). Sequence analysis revealed a relatively low homology among them (50 to $60 \%$ ). Indeed, only one anew clone was isolated after screening in japanese pear fruit cDNA library with previously cloned $\beta$-Gal gene ( $P p G A L 1)$ although at least eight genes are expressed in the fruit, and it indicates that the amino acid sequences used as primers in RT-PCR were well conserved. Bioinformatics analysis of deduced amino acid sequences of the eight $\beta$-Gal cDNA clones predicted the presence of hydrophobic signal peptides at the $\mathrm{N}$-termini (Fig. 1) and that the proteins encoded by these clones are exported to the outside of the plasma membrane (Table 1). 
PPGAL1 -----MGVGIQTMWSILLLFSCIFSAASASVSYDHKAII INGQKRILISGSIHYPRSTPEMWPDLIQKAKDGGLDVIQTYVFWNGHEPSPGKYYFEDRYDLVKFIKLVQ PPGAL2 MVAQRGSPWGLRCLFLCLAVQFALEAAAEYFKPFNVSYDHRALIIDGKRRMLVSAGIHYPRATPEMWPDLIAKSKEGGVDVIQTYAFWSGHEPVRGQYNFEGRYDIVKFANLVG PPGAL3 -- ---MKLLPPLLLLLLLPCWAIALLATAAARNVSYDSRSLI IDGQRKLLISAAIHYPRSVPEMWPKLVQTAKEGGVDVIETYVFWNGHEPSPGNYYFGGRYDLVKFVKIVE PPGAL4 - - - - -MGVGIQTMWSILLLFSCIFSAASASVGYDHKAI I INGQRRILISGSIHYPRSTPGMWPDLIQKAKAGGLDVIQTYVFWNGHEPSPGKYYFEDRYDLVKFIKLVQ PPGAL5 - - - -MEPNSASKLGFFMGLFLLLGFOLVHCAVTYDRKAIVINGQRRILISGSIHYPRSTPEMWEDLIOKAKDGGLDVVETYVFWNVHEPTPGNYNFEGRYDLVRFLKTIO PpGAL6 - - - - - MRILVVVLVLGVLATASYCAKVTYDHRALVIDGKRRVLVSGS IHYPRSTPEMWPDLIQKSKDGGLDVIETYVFWNLHEAVRGQYDFGGRKDLVKFVKTVA PpGAL7 -- --METHSVSKILVLFLTMTLFMASELIHCTTVTYDKKAILINGQRRLLISGSIHYPRSTPEMWEGLIQKAKDGGLDVIDTYVFWNGHEPSPGNYYFEGRYDLVRFIKTVQ PpGAL8 ----MRANSSALSWVLLCCCIVWSSVYVEVTKCNVVYDRKALVIDGQRRLLFSGSIHYPRSTPEMWEGLIQKAKDGGLDAIDTYYFWNLHEPSPGNYNFEGRNDLVRFIKTVH Signal peptide Primer JPG-D1 Primer JPG-D2

PPGAL1 QAGLFVNLRIGPYVCAEWNFGGFPVWLKYVPGIAFRTDNEPFKAAMQKFTEKIVSMMKAEKLFOTOGGPIILSOIENEEGPVEWEIGAPGKAYTKWAAQMAVGLDTGVPWIMCK PPGAL2 ASGLYLHLRIGPYVCAEWNFGGFPVLRDIPGIEFRTNNALFKEEMQRFVKKMVDLMQEEELLSWOGGPIIMMQIENEY GNIEGQFGQKGKEYIKWAAEMALGLGAGVPWVMCK PPGAL3 QAGMHLILRIGPFVAAEWYFGGIPVWLHYVPGTVFRTENKPFKYHMQKFTTFIVDLMKQEKFFASOGGPIILAQVENEYGYYEKDYGEGGKQYAMWAASMAVSQNIGVPWIMCQ PpGAL4 QAGLFVNLRIGPYVCAEWNFGGFPIWLKYVPGIAFRTDNEPFKAAMQKFTEKIVNMIMKAEKLFQTOGGPIILSQIENEEGPVEWEIGAPGKAYTKWAAQMAVGLDTGVPWIMCK PPGAL5 KAGLYAHLRIGPYVCAEWNFGGFPVLKYVPGISFRTDNEPFKRAMQGFTQKIVGLMKSESLFESOGGPIILSOIENEYGAOSKLFGAAGHNYITWAAEMAVGLDTGVPWVMCK PPGAL6 EAGLYVHLRIGPYVCAEWNYGGFPLWLHFIPGIQLRTDNEPFKAEMQRFTAKIVDMMKKEKLYASOGGPIILSQIENEYGNIDRAYGAAAQTYIKWAADMAVSLDTGVPWVMCQ PpGAL7 KAGLFLHLRIGPYVCAEWNFGGFPVWLKYVPGISFRTDNGPFKVAMQGFTQKIVQMMKNEKLFASOGGPIILSQIENEYGPERKALGAPGQNYINWAAKMAVGLDTGVPWVMCK PpGAL8 KAGLYVHLRIGPYICSEWNFGGFPVWLKFVPGISFRTDNEPFKSAMQKFTQKVVQLMKNEKLFESOGGPIILSQIENEYEPESKAFGASGYAYMTWAAKMAVGMGTGVPWVMCK

Glycoside hydrolase family 35 motif

PDGAL1 QEDAPDPVIDTCNGFYCENFKPNKDY-KPKMWTEVWTGWYTEFGGAVPTRPAEDVAFSVARFIQSGGSFLNYYMYHGGTNFGRTAGGPFMATSYDYDAPLDEYGLLREPKWGHL PPGAL2 QVDAPGSIIDACNGYYCDGYKPNSYN-KPTLWTEDWDGWYASWGGRLPHRPVEDLAFAVARFYQRGGSFQNYYMYFGGTNFGRTSGGPFYITSYDYDAPIDEYGLLSEPKWGHL PPGAL3 QFDAPESVINTCNSFYCDQFTPIYQN-KPKIWTENWPGWFKTFGGWNPHRPAEDIAFSVARFFQKGGSVHNYYMYHGGTNFGRTSGGPFITTSYDYEAPIDEYGLPRLPKWGHL PDGAL4 QEDAPDPVIDTCNGYYCENFKPNKVY-KPKMWTEVWTGWYTEFGGAIPTRPAEDLAFSVARFIOSGGSFFNYYMYHGGTNFGRTAGGPFMATSYDYDAPLDEYGLLQOPKWGHL PPGAL5 EEDAPDPVINTCNGFYCDSFSPNRPY-KPTIWTETWSGWFTEFGGPIHQRPVQDLAYAVATFIQKGGSFVNYYMYHGGTNFGRTAGGPFITTSYDYDAPLDEYGLIRQPKYGHL PPGAL6 QDDAPPSVISTCNGFYCDQWTPRLPEKRPKMWTENWSGWFLSFGGAVPQRPVEDLAFAVARFFQRGGTFQNYYMYHGGTNFGRSTGGPFIATSYDYDAPIDEYGLLRQPKWGHL PDGAL7 EDDAPDPMINACNGFYCDGFTPNKPY-KPTMWTEAWSGWFLEFGGTIHHRPVQDLAFAVARFIQRGGSYVNYYMYHGGTNFGRTAGGPFITTSYDYDAPIDEYGLIRQPKYGHL PpGAL8 EDDAPDPVINTCNGFYCDYFSPNKPY-KPTMWTEAWSGWFTEFGGPIYQRPVEDLTFAVARFIQKGGSFINYYMYHGGTNFGRTAGGPFITTSYDYDAPIDEYGLIRRPKYGHL

Primer JPG-DCl

PPGALI RDLHKAIKSCESALVSVD-PSVTKLGSNQEAHVFKSESD-- - - - - - CAAFLANYDAKYSVKVSFGGGQYDLPPWSISILPDCKTEVYSTAKVGSQSSQVQMTPVHS PPGAL2 KDLHAAIKLCEPALVAADSPNYIKLGPKQEAHVYRVNSHTEGLNITSYGSQISCSAFLANIDEHKAASVTFLGQKYNLPPWSVSILPDCRNVVYNTAKVGAQTSIKTVEFDLPL PpGAL3 KQLHRAIKLCEHIMLNSQ-PTNVSLGPSLEADVFTNSSGA- - - - - - - CAAFIANMDDKNDKTVEFRNMSYHLPAWSVSILPDCKNVVFNTAKVGSQSSVVEMLPESLQ PPGAL4 RDLHKAIKSCEHALVAVD-PSVTKLGNNQEAHVFNSKSG-- - - - CAAFLANHDTKYSVRVSFGHGQYDLPPWS ISILPDCKTAVFNTAKVAWKASEVQMKPVYS PPGAL5 KELHKAIKMCERALVSAD-PIITSLGNFQQAYVYTSESGD--..-- - CSAFLSNHDSKSAARVMFNNMHYNLPPWSISILPDCRNVVFNTAKVGVQTSQMQMLPTNIP PPGAL6 KDVHKAIKLCEEAMVATD-PKYSSFGPNVEATVYKTG- - - - - - - SACAAFLANSDTKSDATVTFNGNSYHLPAWSVSILPDCKNVVLNTAKINSAAMIPSFMHHSVI PPGAL7 KELHKAIKLCEHSLLSSE-PTVTSLGTYHQAYVFNSGPRR-- - - - - CAAFLSNFHS-VEARVTFNNKHYDLPPWSVSILPDCRNEVYNTAKVGVQTSHVQMIPTNSR

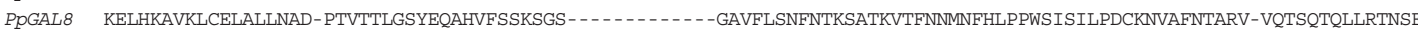

PpGAL1 GFP----.-----WQSFIEETTSSDETDTTTLDGLYEQINITRDTTDYLWYMTDITIGSDEAFLKNGK--SPLLTIFSAGHALNVFINGQLSGTVYGSLENPKLSF PPGAL2 YSGISSOQOFITKNDDLFITKSWMTVKEPVGVWSENNFTVOGILEHLNVTKDOSDYLWHITRIFVSEDDISFWEKNNISAAVSIDSMRDVLRVFVNGOLTEG- - -SVIGHWVKV PPGAL3 LSVGSADKS - - - - - - -LKDLKWDVFVEKAGIWGEADFVKSGLVDHINTTKFTTDYLWYTTSILVGENEEFLKKGS- -SPVLLIESKGHAVHAFVNOELOASAAGNGTHFPFKL PpGAL4 RLP---_-_-_-_--WQSFIEETTTSDETGTTTLDGLYEQIYMTRDATDYLWYMTDITIGSDEAFLKNGK--FPLLTIFSAGHALHVFINGQLSGTVYGSLENPKLTE PPGAL5 MLS--...---..-WESYDEDLTSMDDSSTMTAPGLLEQINVTRDSTDYLWYITSVDIDSSESFLHGGE--LPTLIVQSTGHAVHIFINGQLTGSAFGTRESRRFTY PDGAL6 DDIDSSE---_.-_-ALGSGWSWINEPVGISKKDAFTRVGLLEOINTTADKSDYLWYSLSIDVTSSDTFLODGS - -OTILHVESLGHALHAFINGKPAGRGIITANNGKISV

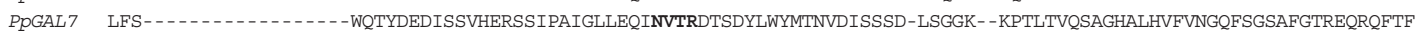
PpGAL8 LHS--...-..---WGIFNEDVSSVAGDTTITVTGLLDQLNITRDSSDYLWYTTSVDIDPSESFLGGGQH--PSLTVQSAGDAMHVFINDQLSGSASGTREHRRFTF

PPGAL1 SQNVNLRSGINKLALLSISVGLPNVGTHFETWNAGVLGPITLKGLNSGT-WDMSGWKWTYKTGLKGEALGLHTVTGSSSVEWVEGPSMAK- - KQPLTWYKATFNAPPGDAPLAI PDGAL2 EOPVKFLKGYNDLVLLTOTVGLONYGAFLEKDAGERGOIKLTGFKNGD-IDLSKLLWTYQVGLKGEFFKIYTIEENEKAGWAELSPDDD- - PSTFIWYKTYFDSPAGTDPVAI PPGAL3 KAPISLKEGKNDIALLSMTVGLQNAGSFYEWVGAGLTS-VKIOGFNNGT-IDLSAYNWTYKIGLEGEHOGLDKEEGFGNVNWISASEPPK- -EQPLTWYKVIVDPPPGDDPVGL PPGAL4 SQNVKLRPGINKLALLSISVGLPNVGTHFETWNTGVLGPISLKGLNTGT-WDMSRWKWTYKIGMKGESLGLHTVTGSSSVDWAEGPSMAQ- - KQPLTWYKATFDAPPGHAPLAI PpGAL5 TGKVNLRAGTNKIALLSVAVGLPNVGGHFEAWNTGILGPVALHGLNOGK-WDLSWOKWTYOVGLKGEAMNLVSONAFSSVEWISGSLIAOKKOQPLTWHKTIFNEPEGSEPLAL PpGAL6 DIPVTFASGKNTIDLLSLTIGLQNYGAFFDKSGAGITGPVQLKGLKNGTTTDLSSQRWTYQIGLQGEDSGFSSGSSSQ- - -WISQPTLPK- - KQPLTWYKATFNAPDGSNPVAL PpGAL7 ADPVNLHAGINRIALLSIAVGLPNVGLHYESWKTGIQGPVFLDGLGNGK-KDLTLHKWFNKVGLKGEAMNLVSPNGASSVGWIRRSLATQTKQT-LKWYKAYFNAPGGNEPLAL PDGAL8 TGNVNLHAGLNKISLLSIAVGLANNGPHFETRNTGVLGPVALHGLDHGT-RDLSWOKWSYOVGLKGEATNLDSPNSISAVDWMTGSLVAOK-OOPLTWYKAYFDEPNGDEPLAL

PPGAL1 DMGSMGKGQIWINGQSVGRHWPGYIARG--SCGDCSYAGTYDDKKCRTHCGEPSORWYHIPRSWLTPNGNLLVVFEEWGGDPSRISLVERGTALDAKKP- - . - . - . - - - - . PPGAL2 DLGSMGKGQAWVNGHHIGRYW-TLVAPEDGCPEICDYRGAYNSDKCSFNCGKPTQTLYHVPRSWLQSSSNLLVILEETGGNPFDISIKLRSAGVLCAQVSESHYPPVQKWFNPD PPGAL3 DMIHMGKGLAWLNGEEIGRYWPRKGPLHG-CVKECNYRGKFDPDKCNTGCGEPTQRWYHVPRSWFKQSGNVLVIFEEKGGDPSKIEFSRRKITGVCALVAENYP-SIDLESW- -

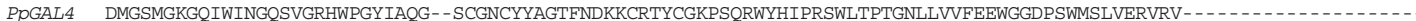
PPGAL5 DMEGMGKGQIWINGQSIGRYWTAFANG---NCNGCSYAGGFRPTKCQSGCGKPTQRYYHVPRSWLKPTQNLLVLFEELGGDPSRISLVKRAVSSVCSEVAEYHPTIKNWHIE- PPGAL6 DFTGMGKGEAWVNGQSIGRYWPTNNAPTSGCPDSCNFRGPYDSNKCRKNCGKPSQELYHVPRSWLKPSGNTLVLFEEIGGDPTQISFATRQIESLCSHVSESHPSPVDTWSS - PDGAL7 DMRRMGKGQVWINGQSIGRYWMAYAKG---DCSSCSYIGTFRPTKCQLHCGRPTQRWYHVPRSWLKPTQNLVVVFEELGGDPSKITLVRRSVAGVCGDLHENHPNAENFDVDPDGAL8 DMGSMGKGOVWINGOSIGRYWTIYADS---DCSACTYSGTFRPKKCOFGCOHPTOOWYHVPRSWLKPSKNLLVVFEEIGGDVSKVALVKKSVTSVCAEVSENHPRITNWHTESH

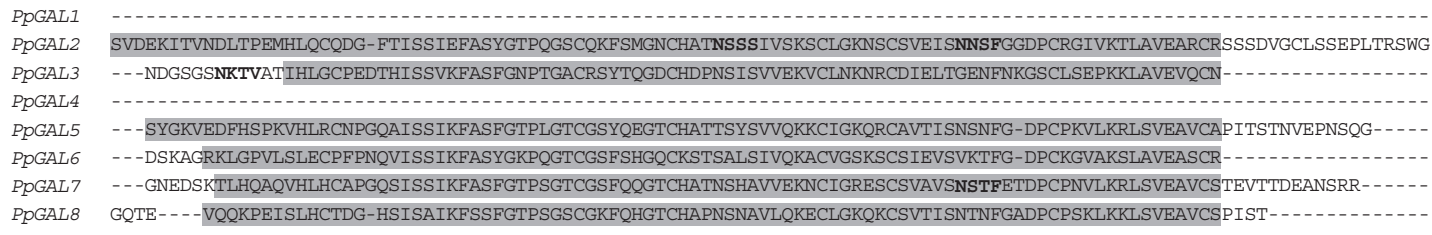

Galactose binding lectin domain

Fig. 1. Deduced amino acid sequence alignment of japanese pear $\beta$-galactosidases ( $P p G A L s$ ) open reading frames. Regions of identity are highlighted including the consensus sequence for the putative active site of the glycoside hydrolase family 35 . Predicted signal peptide at $\mathrm{N}$-terminal and galactose binding lectin domain at C-terminal are gray boxed. Putative N-linked glycosylation sites are set bold. 


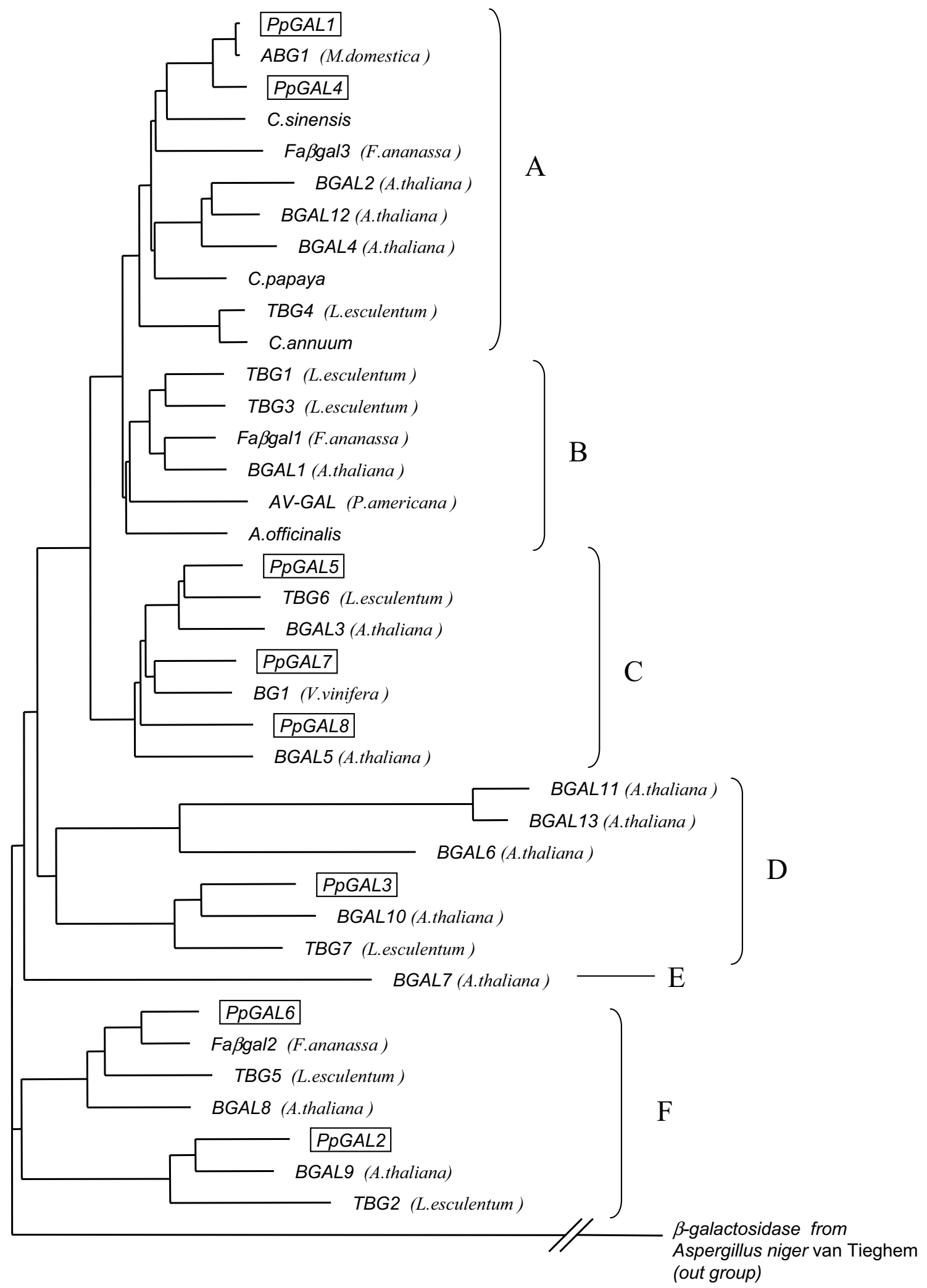

Fig. 2. Phylogenetic tree of the alignment of japanese pear $\beta$-galactosidases ( $P p G A L s$ ) deduced amino acid sequences with other $\beta$-galactosidase genes. The phylogenetic tree was drawn using CLUSTAL W suite of programs. The GenBank accession numbers are; PpGAL1, AB046543; PpGAL2, AB190363; PpGAL3, AB 190364; PpGAL4, AB190365; PpGAL5, AB190366; PpGAL6, AB190367; PpGAL7, AB190368; PpGAL8, AB190369; ABG1, L29451; C. sinensis, AY029198; Faß-gall, AJ278703; Faß-gal2, AJ278704; Faß-gal3, AJ278705; BGAL1, AJ270297; BGAL2, AJ270298; BGAL3, AJ270299; BGALA, AJ270300; BGAL5, AJ270301; BGAL6, AJ270302; BGAL7, AJ270303; BGAL8, AJ270304; BGAL9, AJ270305; BGAL10, AJ270306; BGAL11, AJ270307; BGAL12, AJ270308; BGAL13, AJ270309; C. papaya, AF064786; TBG1, AF023847; TBG2, AF154420; TBG3, AF154421; TBG4, AF020390; TBG5, AF154423; TBG6, AF154424; TBG7, AF154422A; C. annuum, AY029226; AV-GAL, AB061017; A. officinalis, X77319; and BG1, AY043231. 
A

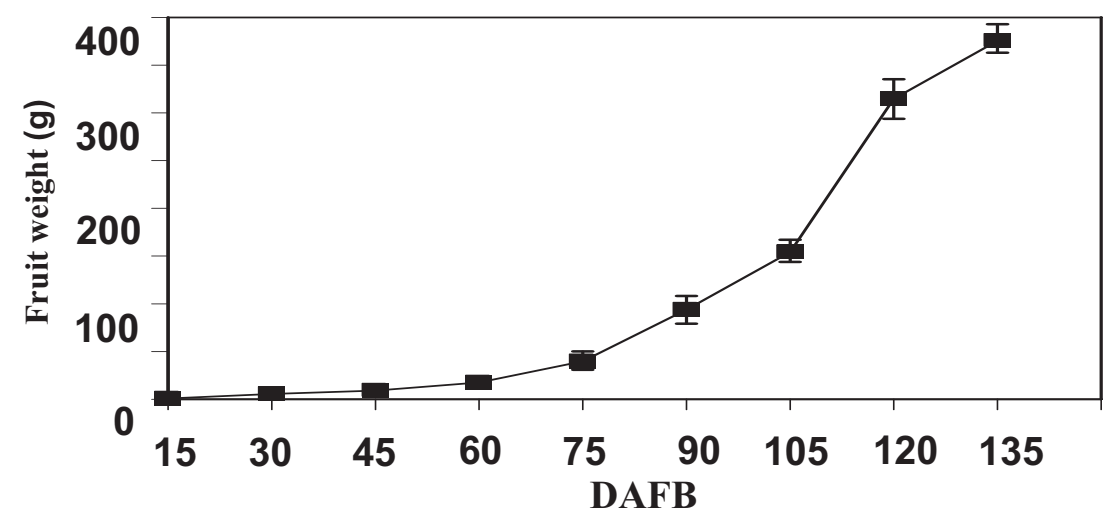

B

Fruit

C

153045607590105120135

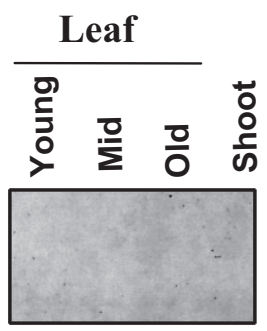

PpGAL2
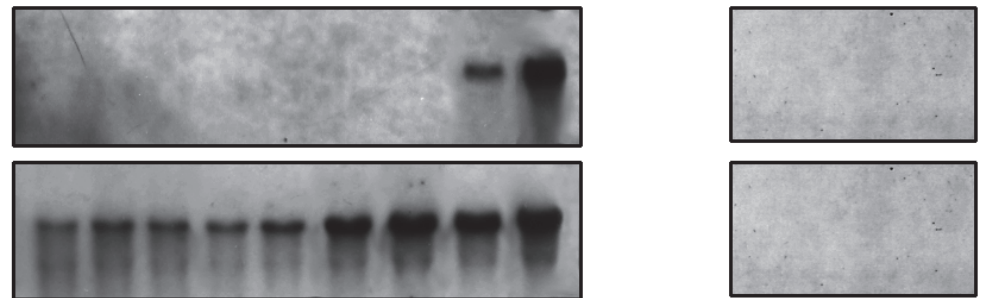

PpGAL3
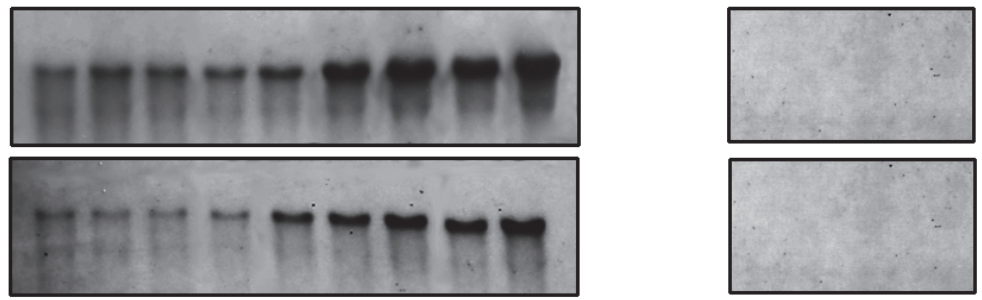

PpGAL4
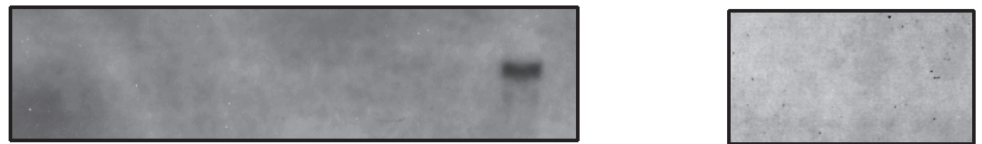

PpGAL5
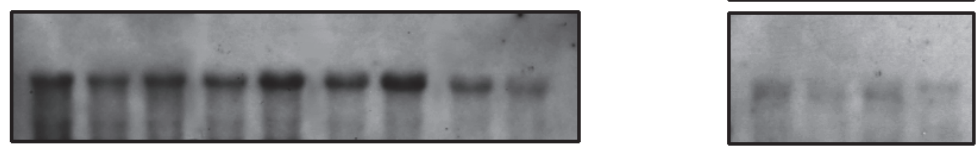

PpGAL6
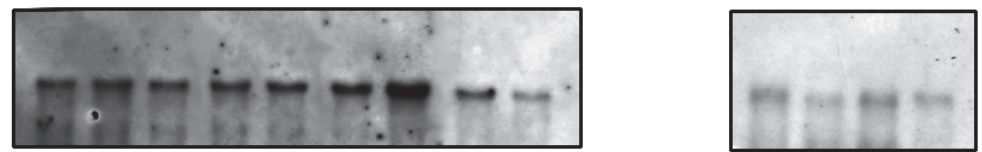

PpGAL 7
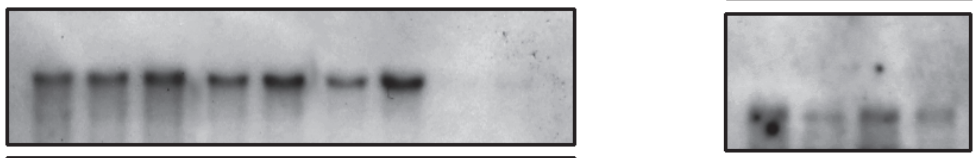

PpGAL8
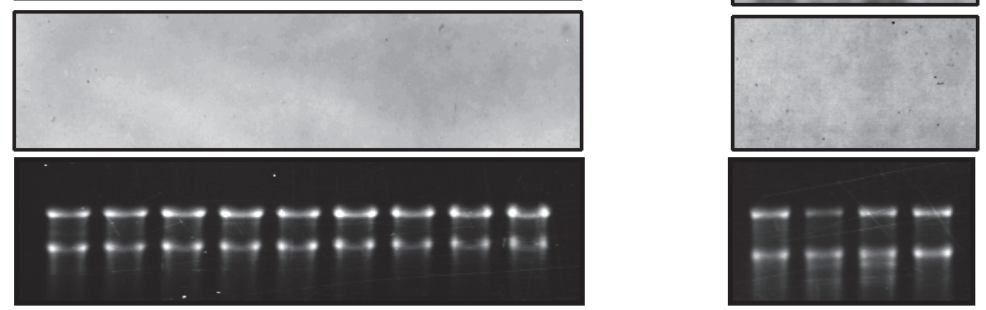

Fig. 3. Fruit growth curve (A), RNA gel-blot analysis of $\beta$-galactosidase ( $P p G A L)$ mRNA levels in fruit during growth (B), and in leaves and shoot (C) in 'Housui'. Data in panel A are shown as means \pm SD $(\mathrm{n}=15)$. In panel B and C, $1 \mu \mathrm{g}$ of total RNA extracted from fruit at the indicated days after full bloom (DAFB), leaves and shoot was loaded in each lane. Young, young leaves (pre-expanding); Mid, expanding leaves ( $<5 \mathrm{~cm}$ long); Old, mature leaves (fully expanded, 7 to $10 \mathrm{~cm}$ long); and shoots $(\approx 5 \mathrm{~mm}$ diameter) were sampled. 
A

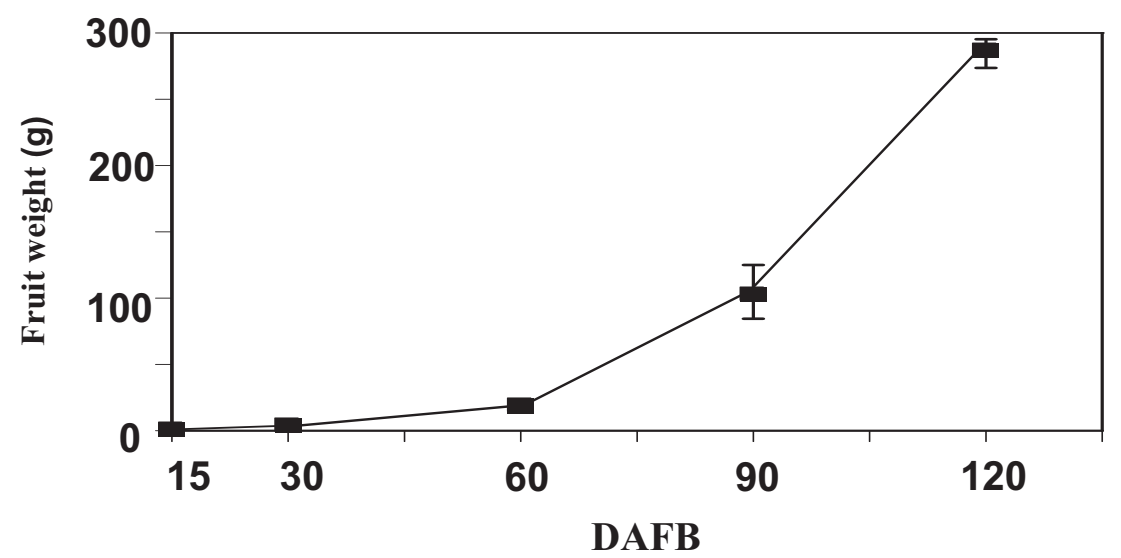

B

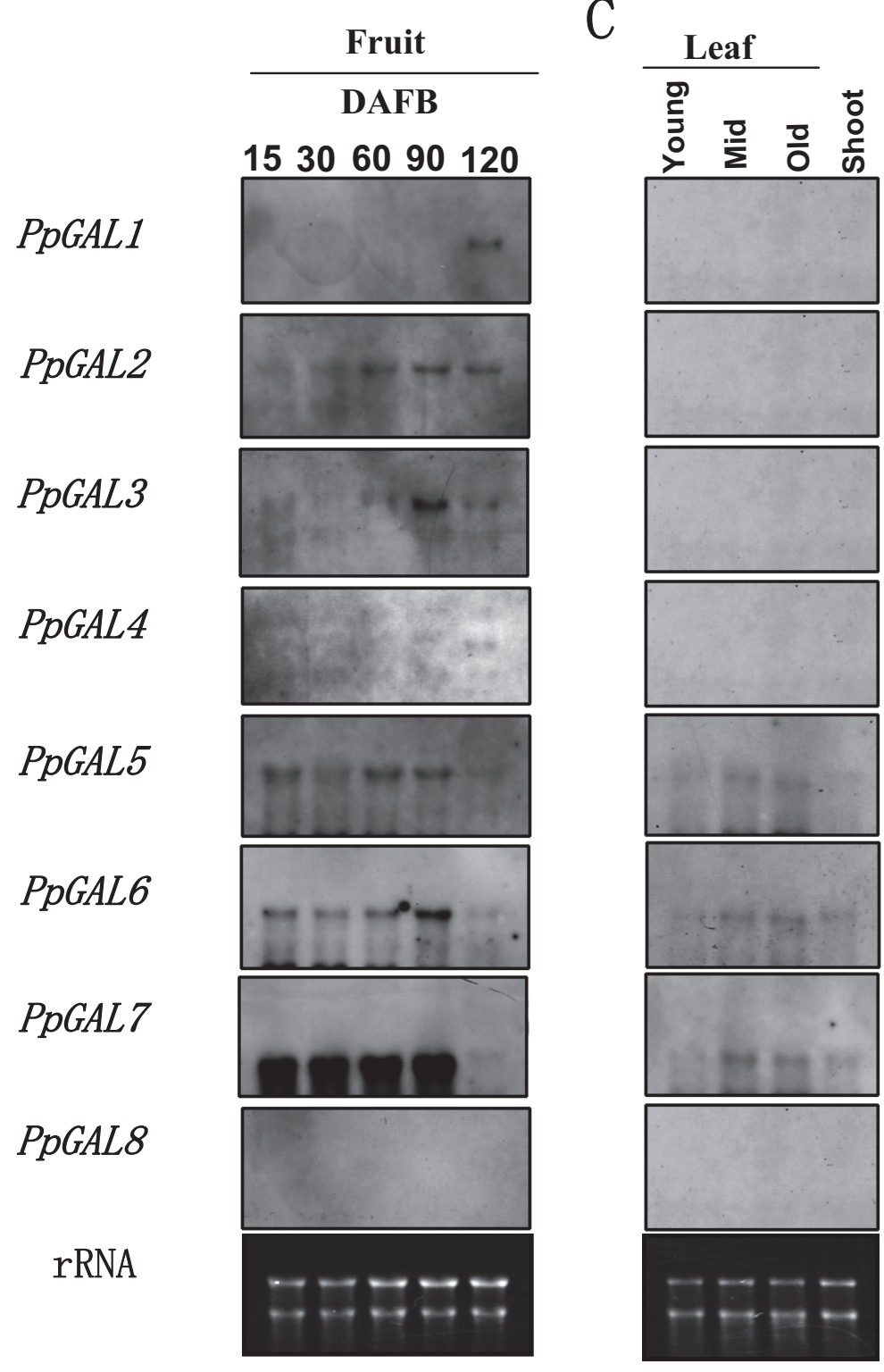

C

Fig. 4. Fruit growth curve (A), RNA gel-blot analysis of $\beta$-galactosidase $(P p G A L)$ mRNA levels in fruit during growth $(\mathbf{B})$ and in leaves and shoot $(\mathbf{C})$ in `Kousui` Data in panel A are shown as means \pm SD $(\mathrm{n}=15)$. In panel B and C, $1 \mu \mathrm{g}$ of total RNA extracted from fruit at the indicated days after full bloom (DAFB), leaves and shoots were loaded in each lane. Young, Mid, and Old are the stages of leaves sampled, and the details were described in Fig. 3. 
A

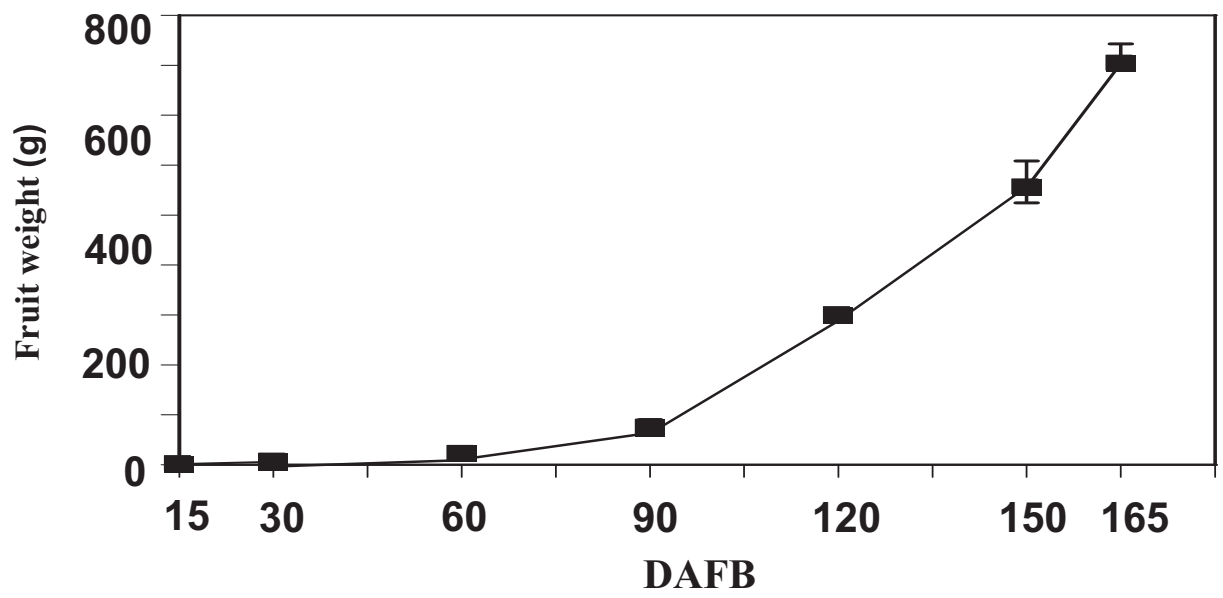

B

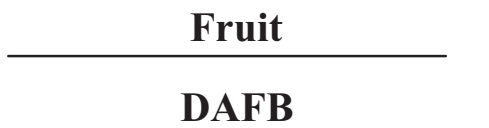

$\mathrm{C}$ Leaf

15306090120150165

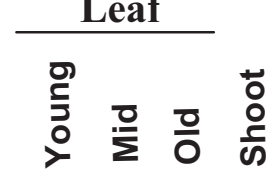

\section{PpGAL1}

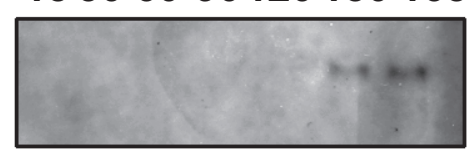

PpGAL2
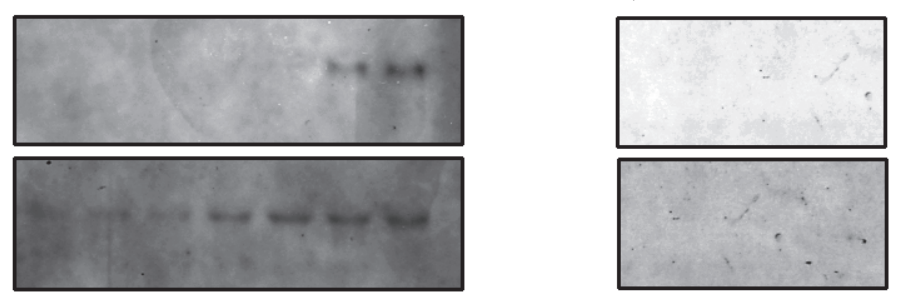

PpGAL3
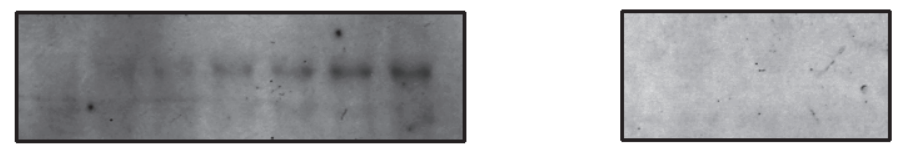

PpGAL4
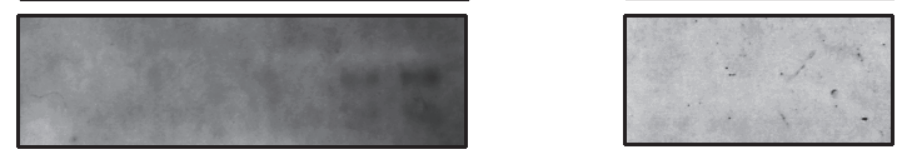

PpGAL5
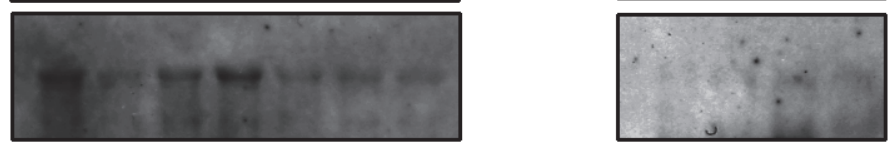

PpGAL6
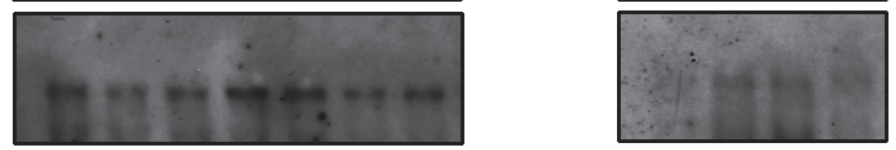

PpGAL 7
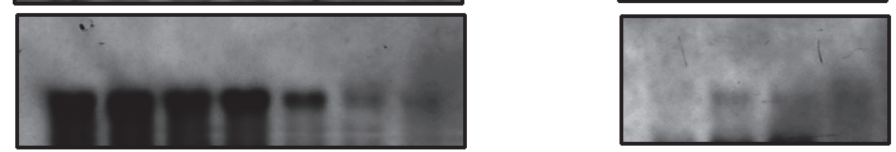

PpGAL8
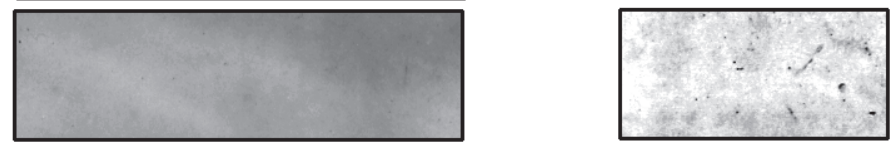

rRNA
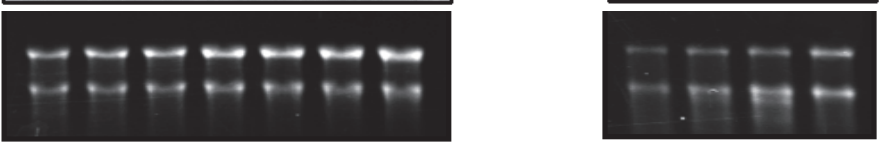

Fig. 5. Fruit growth curve (A), RNA gel-blot analysis of $\beta$-galactosidase (PpGAL) mRNA levels in fruit during growth (B) and in leaves and shoot (C) in `Niitaka`. Data in panel A are shown as means \pm SD $(\mathrm{n}=15)$. In panel B and C, $1 \mu \mathrm{g}$ of total RNA extracted from fruit at the indicated days after full bloom (DAFB), leaves and shoot was loaded in each lane. Young, Mid, and Old are the stage of leaves sampled and the details were described in Fig. 3. 
These imply that the eight $\beta$-Gals are active against the cell wall (extracellular) and they may all be involved in cell wall galactosyl modification at one stage or another during japanese pear fruit growth and ripening.

Smith and Gross (2000) categorized $\beta$-Gal family into two groups based on their predicted molecular size and other characteristics. The members of the larger group reported here contain galactose-binding lectin domain (Pfam accession no. PF02140) at their carboxyl termini of the proteins that has previously been reported as SUEL (sea urchin egg lectin, PROSITE accession no. PS50228) type lectin domain. This domain has been observed in strawberry (Fragaria xananassa Duch.) $\beta$-Gal although its function has not been established (Trainotti et al., 2001), but if proven functional, it could affect the biochemical characteristics of the enzyme containing it. Evolutionary relationship was inferred from phylogenetic tree through an alignment of the deduced amino acid sequences of the PpGALs with 30 plants $\beta$ Gal homologues. The analysis revealed the existence of at least six subfamilies of $\beta$-Gal genes (Fig. 2), although phylogenetic tree is drawn by only sequence similarities rather than those of physiological roles. The $\beta$-Gal genes isolated from apple (Ross et al., 1994), sweet orange [Citrus sinensis (L.) Osb.] (Wu and Burns, 2004), papaya (Carica papaya L.) (Othman et al., 1998), tomato (TBG4), strawberry (Faßgal3, Trainotti et al., 2001), and japanese pear ( $P p G A L 1$ and $P p G A L 4)$ among others were classified into cluster $A$ and galactose-binding lectin domain was absent in this group.

Accumulation of mRNAs for $P p G A L 1$ and $P p G A L 4$, classified into cluster A, was observed at the onset of fruit ripening and no expression was detected in immature fruit. These genes were not expressed in leaves and shoots (Fig. 3). It is plausible, therefore, that PpGAL1 and PpGAL4 genes are not only fruit-specific but also ripening-specific. Tomato TBG4, which encodes for $\beta-\mathrm{Gal}$ II, is only expressed in ripening fruit and is up-regulated by ethylene (Moctezuma et al., 2003; Smith and Gross, 2000; Smith et al., 2002) belongs to the same cluster as PpGAL1 and PpGAL4. These $P p G A L$ s that exhibit changes in mRNA abundance at the onset of ripening and during the onset of autocatalytic ethylene production are of particular interest with respect to understanding the role they play in japanese pear fruit softening. However, lack of experimental data does not allow us to arrive at this conclusion with respect to PpGAL1 and PpGAL4. The characteristics of $\beta$-Gal cDNA clones isolated from apple ( $p A B G 1)$, tomato $(T B G 4)$, and japanese pear $(P p G A L 1)$ indicate that they encode for the softening-related $\beta$-Gal isozymes as matched by their primary structure and deduced amino acid sequence of related clones (Ross et al., 1994; Smith and Gross, 1998; Tateishi et al., 2001b). Recently, Smith et al (2002) demonstrated that downregulation of $T B G 4$ expression in tomato fruit results in delayed fruit softening. Therefore $P p G A L 1$ and $P p G A L 4$ may contribute to cell wall disassembly during fruit ripening and they might be the crucial $\beta$-Gals for determining japanese pear fruit softening. Other $\beta$-Gal genes classified into cluster A may also play a similar role during fruit ripening.

Expression of PpGAL2 and PpGAL3 mRNAs was detected throughout fruit growth and ripening. The levels of mRNA accumulation for both genes increased with fruit expansion and were highest at the onset of fruit ripening (Fig. 3). The PpGAL2 and PpGAL3 mRNAs were not detected in leaves and shoot as was observed for the fruit-specific expression of tomato TBG2 (Smith and Gross, 2000) classified in the same cluster as PpGAL2 (cluster F, Fig. 2). Therefore, $P p G A L 2$ and $P p G A L 3$ may be responsible for galactose metabolism in rapidly expanding fruit cell wall as well as cell wall disassembly in ripening fruit. Indeed $T B G 7$ isolated from tomato fruit that is transiently expressed very early and late in fruit development (Smith and Gross, 2000) is grouped in the same cluster as PpGAL3 (cluster D).

PpGAL5, $P p G A L 7$, and $P p G A L 8$ were classified in the same cluster (cluster C) as TBG6 (Smith and Gross, 2000) and BG1 (Nunan et al., 2001) from tomato and grape berry (Vitis vinifera L.), respectively (Fig. 2). TBG6 mRNA accumulation is limited to preripening stage of tomato fruit development. In grape berry $\beta-$ Gallo is only detectable in the early stages of development, suggesting that like these $P p G A L$ genes, it encodes for a $\beta-G a l$ active on cell wall during the early stages of development (Barnavon et al., 2000). In ripening impaired mutant tomatoes, rin and nor fruit, the accumulation of TBG6 mRNA continued through ripening stage (Smith and Gross, 2000). PpGAL5 and PpGAL7 expression decreased to low levels in the ripe fruit. Moreover, mRNAs of PpGAL5 and PpGAL7 were also detected in leaves and shoots (Fig. 3). It is possible that PpGAL5 and PpGAL7 genes are involved in general galactose metabolism in growing tissues and the expression of the genes may be suppressed by the ripening signal. mRNA for $P p G A L 8$, which is classified in the same group, was not detected at any stage of fruit growth and ripening by the Northern blot analysis but was detected in only 15 DAFB immature fruit by RT-PCR method (data not shown). In japanese pear, cell division in fruit tissue occurs until $30 \mathrm{~d}$ after anthesis (Yamaki and Kakiuchi, 1979), which raises the possibility that $P p G A L 8$ may be involved in galactose metabolism during cell division.

PpGAL6 was clustered together with Faßgal2, TBG5, and $B G A L 8$ isolated from strawberry, tomato, and arabidopsis, respectively. It has been reported that Faßgal2 is expressed in stolon and immature leaves or fruit, and its mRNA level decrease with fruit ripening (Trianotti et al., 2001). Thus, PpGAL6 may be responsible for galactose conversion for synthesis of cell wall polysaccharides with growth of fruit and other tissue. In strawberry, none of the three $\beta$-Gal genes was limited to the fruit tissue only (Trianotti et al., 2001).

There are many of japanese pear cultivars grown in Japan and one of their main differences among them is the length of the development period and onset of fruit ripening. In this study we used two additional japanese pear cultivars ('Kousui' and 'Niitaka') to compare the expression pattern of the $\beta$-Gal genes. 'Kousui' and 'Niitaka' are early-ripening and late-ripening, respectively, compared to 'Housui.' Therefore, developmental periods of 'Kousui' and 'Niitaka' are also shorter and longer, respectively, than that of 'Housui.' In all the cultivars, the expression of $P p G A L 1$ and PpGALA was detected on different days; however, based on fruit growth curve they were all expressed at the ripening stage (Figs. 4 and 5). Expression patterns of the other $\beta$-Gal genes were also compared based on physiological stage of fruit growth and ripening. In 'Kousui' and 'Niitaka', expression of PpGAL2 and PpGAL3 was in fruit-specific and continued throughout fruit growth and ripening, PpGAL5, PpGAL6, and $P p G A L 7$ expression decreased upon the onset of fruit ripening. These changes observed in 'Kousui' and 'Niitaka' are similar to those observed in 'Housui' despite all having different fruit development periods (Figs. 4 and 5). The overlapping expression of the japanese pear $\beta$-Gal genes, regardless of the cultivars, may imply that a coordinated effort of this enzyme is necessary for cell wall modifications that occur during cell division, cell growth, and fruit ripening. Furthermore, expression of $\beta-\mathrm{Gal}$ 
genes seemed to be developmentally regulated probably through hormonal signal transduction regulation since each of the $\beta-\mathrm{Gal}$ genes was expressed in a similar physiological manner rather than chronologically. We are currently investigating the role of ethylene for $\beta$-GAL genes expression using 1-methylcyclopropene that blocks ethylene perception.

In conclusion, the results presented here indicate that the japanese pear fruit $\beta$-Gal comprise of a gene family with individual members showing distinct and overlapping expression during different phases of fruit development. Moreover, the expression pattern of the genes was similar in the three cultivars. Some of the genes are not only fruit-specific but also ripening-specific. The $P p G A L 1$ and $P p G A L 4$ genes are involved in ripening-associated cell wall disassembly; $P p G A L 5, P p G A L 6$, and $P p G A L 7$ in rapid cell expansion; and $P p G A L 2$ and $P p G A L 3$ genes, if their target is the cell wall, are involved in both cell expansion and cell wall disassembly during japanese pear fruit ripening while PpGAL8 could be involved in cell division. On the basis of specificity, the genes can be separated into two classes: 1) those expressed in fruit only (PpGAL1, PpGAL2, PpGAL3, and PpGAL4) and 2) those expressed in fruit and other tissues (PpGAL5, PpGAL6, and $P p G A L 7)$. It is, therefore, clear that $P p G A L 1$ and $P p G A L 4$ and probably $P p G A L 2$ and $P p G A L 3$ play important roles in softening during japanese pear fruit ripening.

\section{Literature Cited}

Barnavon, L., T. Doco, N. Terrier,A. Ageoges, C. Romieu, and P. Pellerin. 2000 . Analysis of cell wall neutral sugar composition, $\beta$-galactosidase activity and related cDNA clone throughout the development of Vitis vinifera grape berries. Plant Physiol. Biochem. 38:289-300.

Brummell, D.A. and M.H. Harpster. 2001. Cell wall metabolism in fruit softening and quality and its manipulation in transgenic plants. Plant Mol. Biol. 47:311-340.

Carey, A.T., K. Holt, S. Picard, R. Wilde, G.A. Tucker, C.R. Bird, W. Schuch, and G.B. Seymour. 1995. Tomato exo-(1->4)- $\beta$-D-galactanase. Isolation, changes during ripening in normal and mutant tomato fruit, and characterization of a related clone. Plant Physiol. 108:1099-1107.

Carrington, C.M. and R. Pressy. 1996. $\beta$-Galactosidase II activity in relation to changes in cell wall galactosyl composition during tomato ripening. J. Amer. Soc. Hort. Sci. 121:132-136.

Cosgrove, D.J. 1997. Assembly and enlargement of primary cell wall in plants. Annu. Rev. Cell Dev. Biol. 13:171-201.

Downs, C.G. and C. Almira. 1995. A beta-galactosidase (Genbank X84684) cDNA homolog from Broccoli (Brassica oleracea L.) (PGR95-017). Plant Physiol. 108:1342.

Emanuelsson, O., H. Nielsen, S. Brunak, and G. von Heijne. 2000. Predicting subcellular localization of proteins based on their N-terminal amino acid sequence. J. Mol. Biol. 300:1005-1016.

Henrissat, B. 1998. Glycosidase families. Biochem. Soc. Trans. 26:153-156.

King, G.A. and K.M. Davies. 1995. Cloning of a harvest-induced betagalactosidase from tips of harvested asparagus spears. Plant Physiol. 419-420.

Kitagawa, Y., Y. Kanayama, and S. Yamaki. 1995. Isolation of $\beta$-galactosidase fractions from japanese pear: Activity against native cell wall polysaccharides. Physiol. Plant. 93:545-550.

Moctezuma, E., D.L. Smith, and K.C. Gross. 2003. Effect of ethylene on
mRNA abundance of three $\beta$-galactosidase genes in wild and mutant tomato fruit. Postharvest Biol. Technol. 28:207-217.

Nakai, K. and M. Kanehisa. 1992. A knowledge base for predicting protein localization sites in eucaryotic cells. Genomics 14:897-911.

Nielsen, H., J. Engelbrecht, S. Brunak, and G. von Heijne. 1997. Identification of prokaryotic and eukaryotic signal peptides and prediction of their cleavage sites. Protein Eng. 10:1-6.

Nunan, K.J., C. Davies, S.P. Robinson, and G.B. Fincher. 2001. Expression patterns of cell wall-modifying enzymes during grape berry development. Planta 214:257-264.

Othman, R., T.S. Choo, Z.M. Ali, Z. Zainal, and H. Lazan. 1998. A full-length beta-galactosidase cDNA sequence from ripening papaya. Plant Physiol. 118:1102.

Rose, J.K.C., H.H. Lee, and A.B. Bennett. 1997. Expression of a divergent expansin gene is fruit-specific and ripening-regulated. Proc. Natl. Acad. Sci. USA 94:5955-5960.

Rose, J.K.C. and A.B. Bennett. 1999 Cooperative disassembly of the cellulose-xyloglucan network of plant cell walls: Parallels between cell expansion and fruit ripening. Trends Plant Sci. 4:176-183.

Rose, J.K.C., C. Catala,Z.H. Gonzalez-Carranza, and J.A. Roberts. 2003. Cell wall disassembly. Annu. Plant Rev. 8:264-324.

Ross, G.S., T. Wegrzyn, E.A. MacRae, and R.J. Redgwell. 1994. Apple $\beta$-galactosidase. Activity against cell wall polysaccharides and characterization of a related cDNA clone. Plant Physiol. 106:521-528.

Smith, D.L., D.A. Starrett, and K.C. Gross. 1998. A gene coding tomato fruit $\beta$-galactosidase II is expressed during fruit ripening. Plant Physiol. 117:417-423.

Smith, D.L. and K.C. Gross. 2000. A family of at least seven $\beta$-galactosidase genes is expressed during tomato fruit development. Plant Physiol. 123:1173-1183.

Smith, D.L., J.A. Abbott, K.C. Gross. 2002. Down-regulation of tomato $\beta$-galactosidase 4 results in decreased fruit softening. Plant Physiol. 1755-1762.

Tateishi,A., Y. Kanayama, and S. Yamaki. 1996. $\alpha$-L-Arabinofuranosidase from cell walls of japanese pear fruits. Phytochemistry 42:295-299.

Tateishi, A., H. Inoue, H. Shiba, and S. Yamaki. 2001b. Molecular cloning of $\beta$-galactosidase from japanese pear (Pyrus pyrifolia) and its gene expression with fruit ripening. Plant Cell Physiol. 42:492-498.

Tateishi, A., H. Inoue, and S. Yamaki. 2001a. Fluctuations in activities of three $\beta$-galactosidase isoforms from ripening avocado (Persea americana) fruit and their different activities against its cell wall polysaccharides as substrates. J. Jpn. Soc. Hort. Sci. 70:586-592.

Tateishi, A., H. Inoue, and S. Yamaki. 2002. Cloning and expression of $\beta$-galactosidase cDNA related to softening avocado (Persea americana) fruit. J. Jpn. Soc. Hort. Sci. 71:48-55.

Thompson, J.D., D.G. Higgins, and T.J. Gibson. 1994. CLUSTAL W: Improving the sensitivity of progressive multiple sequence alignment through sequence weighting, position-specific gap penalties and weight matrix choice. Nucleic Acids Res. 22:4673-4680.

Trainotti, L., R. Spinello, A. Piovan, S. Spolaore, and G. Casadoro. 2001. $\beta$-Galactosidase with a lectin-like domain are expressed in strawberry. J. Expt. Bot. 52:1635-1645.

Wan, C-Y. and T.A. Wilkins. 1994. A modified hot borate method significantly enhances the yield of high-quality RNA from cotton (Gossypium hirsutum L.). Anal. Biochem. 223:7-12.

Wu, Z. and J.K. Burns. 2004. A $\beta$-galactosidase gene is expressed during mature fruit abscission of 'Valencia' orange (Citrus sinensis). J. Expt. Bot. 55:1483-1490.

Yamaki, S. and N. Kakiuchi. 1979. Changes in hemicellulose-degrading enzymes during development and ripening of japanese pear fruit. Plant Cell Physiol. 20:301-309. 